\title{
Endoscopic Mucosal Resection with Circumferential Incision for the Treatment of Large Sessile Polyps and Laterally Spreading Tumors of the Colorectum
}

\author{
Young Mi Hong, Hyung Wook Kim, Su Bum Park, Cheol Woong Choi and Dae Hwan Kang \\ Department of Internal Medicine, Pusan National University School of Medicine and Research Institute for Convergence of Biomedical Science and \\ Technology, Pusan National University Yangsan Hospital, Yangsan, Korea
}

See commentary on page $4-5$

\begin{abstract}
Background/Aims: Endoscopic mucosal resection (EMR) is the standard treatment for colorectal polyps such as adenomas and early cancers with no risk of lymph node metastasis. However, endoscopic resection of large colorectal polyps ( $\geq 20$ mm diameter) is difficult to perform. We evaluated the clinical outcomes of EMR with circumferential incision (EMR-CI) for the resection of large sessile polyps (Is) and laterally spreading tumors (LSTs) in the colorectum.
\end{abstract}

Methods: Between February 2009 and March 2011, we resected 80 large colorectal polyps by EMR-CI. We retrospectively investigated the en bloc resection rate, histologic complete resection rate, recurrence rate, and complications.

Results: The median polyp size was approximately $25 \mathrm{~mm}$ (range, 20 to 50), and the morphologic types included Is (13 cases), LSTgranular (37 cases), and LST-nongranular (30 cases). The en bloc and complete histologic resection rates were $66.3 \%$ and $45.0 \%$, respectively. The recurrence rate was $0 \%$ (median follow-up duration, 23 months), and perforation occurred in five cases (6.3\%).

Conclusions: EMR-CI is an effective treatment modality for 20 to $30 \mathrm{~mm}$-sized colorectal polyps, and may be considered as a second line therapeutic option if ESD is difficult.

Key Words: Colorectal polyps; Endoscopic mucosal resection; Circumferential incision

\section{INTRODUCTION}

Endoscopic mucosal resection (EMR) has been widely used to treat colorectal polyps because of its attractive clinical advantages including simplicity, speed, and low complication rate. ${ }^{1-7}$ However, piecemeal resection frequently occurred in polyps exceeding $20 \mathrm{~mm}$ in diameter (49\% to $100 \%),{ }^{8-10}$ and

Received: February 24, 2014 Revised: May 12, 2014

Accepted: June 2, 2014

Correspondence: Hyung Wook Kim

Department of Internal Medicine, Pusan National University School of Medicine and Research Institute for Convergence of Biomedical Science and Technology, Pusan National University Yangsan Hospital, 20 Geumo-ro, Yangsan 626-787, Korea

Tel: +82-55-360-1534, Fax: +82-55-360-1536

E-mail: mdkhwook@gmail.com

(c) This is an Open Access article distributed under the terms of the Creative Commons Attribution Non-Commercial License (http://creativecommons.org/ licenses/by-nc/3.0) which permits unrestricted non-commercial use, distribution, and reproduction in any medium, provided the original work is properly cited. the local recurrence of polyps resected in this manner has been reported to be $25 \%$ to $50 \%$, compared with a value of $7.7 \%$ to $21.9 \%$ for en bloc resection. ${ }^{11,12}$

As endoscopic submucosal dissection (ESD) has been reported to achieve high en bloc resection rates $(84 \%)^{13}$ and low recurrence rates in the colorectum, it is expected to overcome the limitations of EMR and offer better clinical outcomes. ${ }^{14}$ ESD is a modified form of EMR, and has been established as a standard technique for the treatment of early gastric cancers and adenomas. On the other hand, ESD has not yet been established as a standard intervention in the colorectum due to its unique organ-specific characteristics, technical difficulty, and high complication rate. To overcome these drawbacks, modified endoscopic procedures have been introduced, such as ESD with snaring and EMR with circumferential incision (EMR-CI). ${ }^{15-17}$

EMR-CI was first reported by Hirao et al. ${ }^{18}$ in 1986, and has 
been used to endoscopically treat early gastric cancers. Several studies have reported high en bloc resection rates (55.1\% to $68.0 \%)$ and low recurrence rates $(0.0 \%$ to $17.8 \%)$ for EMR-CI in cases involving large colorectal polyps. ${ }^{17,19,20}$ Therefore, EMR-CI may offer similar clinical outcomes to ESD, and may even provide additional advantages such as relatively simple technique and shorter procedure times. The aim of the present study was to evaluate the efficacy and safety of EMR-CI for the treatment of large ( $\geq 20 \mathrm{~mm}$ diameter) sessile polyps (Is) and laterally spreading tumors (LSTs) in the colorectum.

\section{MATERIALS AND METHODS}

\section{Patients}

This study was performed in patients who were diagnosed with large ( $\geq 20 \mathrm{~mm}$ diameter) colorectal polyps and treated by EMR-CI at Pusan National University Yangsan Hospital between February 2009 and March 2011. A total of 80 patients were enrolled, of which 13 had Is polyps and 67 had LSTs. Exclusion criteria were the presence of colorectal polyps with stalks, or endoscopic findings of deep submucosal invasion such as ulceration, firm consistency, friability, and spontaneous bleeding. Written informed consent was obtained from all patients, and the study was approved by the Institutional Review Board of Pusan National University Yangsan Hospital (PNUYH IRB No. 05-2014-028).

\section{Classification of lesion morphology and location}

Lesions were classified as either 1) Is polyps, which are protrusion lesions with a height of $\geq 2.5 \mathrm{~mm}$; or 2) LSTs, which are superficial and elevated lesions with a height of $<2.5 \mathrm{~mm}$ and a lateral diameter of $>10 \mathrm{~mm}$, and classified into two subgroups, namely granular (LST-Gs) and nongranular (LST-NGs). ${ }^{21}$ The right colon included the cecum, and the ascending and transverse colon. The left colon included the descending and sigmoid colon.

\section{Endoscopic procedure}

For colonic preparation, we used $4 \mathrm{~L}$ of polyethylene glycol solution on the day of the procedure, or as a divided dose during the day before the procedure and on the day of the procedure. A single-channel colonoscope (CF-H260AI; Olympus Optical Co., Tokyo, Japan) or a single-channel upper endoscope (GIF-H260; Olympus Optical Co.) and a high-frequency generator with an automatically controlled system (VIO300; ERBE Elektromedizin GmbH, Tübingen, Germany) were used for EMR-CI. We used the electrosurgical units as follows: $\mathrm{CI}$, dry cut (effect-2, $30 \mathrm{~W}$ ); snare resection mode, endocut Q (effect-1, cut duration-1, cut interval-3); coagulation mode; and soft coagulation (effect-5, $50 \mathrm{~W}$ ). A cap-pitted endoscope with a transparent attachment (D-201-11804 or D-201-14304; Olympus Optical Co.) was used in all procedures. A mixed solution of glycerol (10\% glycerin and 5\% fructose injection; CJ Pharma, Seoul Korea), epinephrine, and indigo carmine was used for submucosal injection. Endoscopic procedures were performed by an endoscopist who was highly experienced (10 years) in diagnostic and therapeutic colonoscopy, and who had a history of performing more than 500 EMR procedures per year. After sufficient injection into the peripheral submucosa of the polyp, CI was performed $2 \mathrm{~mm}$ away from the polyp using a dual knife (Olympus KD-650D), and additional trimming was performed to allow easy snaring. The polyp was then resected using a 25 or $35 \mathrm{~mm}$ oval snare (Fig. 1). Piecemeal resection was performed in cases where snaring was difficult due to large polyp size or difficult polyp location after CI (Fig. 2). If residual polyp tissue was suspected after en bloc resection, ablation and removal were performed using hot biopsy. For piecemeal resection, ablation and removal were performed using hot biopsy in all cases. All patients were admitted on the day before the procedure, and unless complications occurred, they were discharged 2 days after EMR-CI. Follow-up colonoscopy was performed 3 to 6 months after the procedure, depending on the margin status or polyp histology, and again after 1 to 2 years to assess local recurrence. We evaluated post-EMR-CI scarring by narrow band imaging or indigo carmine spraying, and a biopsy was performed if recurrence was suspected.

\section{Pathologic evaluation}

All resected specimens were fixed in 10\% formalin, cut into 2-mm slices, and microscopically evaluated for histologic type, depth of invasion, and lateral and vertical cut margins. We defined complete endoscopic resection as the complete removal of endoscopically visible tumor regardless of en bloc resection. Histologically complete resection was defined as the presence of lateral and vertical margins free of adenoma and adenocarcinoma, independent of the histologic features. In addition, the depth of submucosal invasion, lymphovascular invasion, and tumor budding were evaluated. If the cancer invaded deeper than 1,000 $\mu \mathrm{M}$ into the submucosa, or had unfavorable pathologic features (lymphovascular invasion, poor differentiation, or tumor budding), radical surgery was recommended.

\section{Statistical analysis}

All values in this study are presented as medians (range). Comparisons were made using the chi-square test, Fisher exact test, and Student $t$-test. $p$-values of $<0.05$ were considered to be statistically significant. All statistical analyses were performed using the SPSS 18.0 version (SPSS Inc., Chicago, IL, USA). 


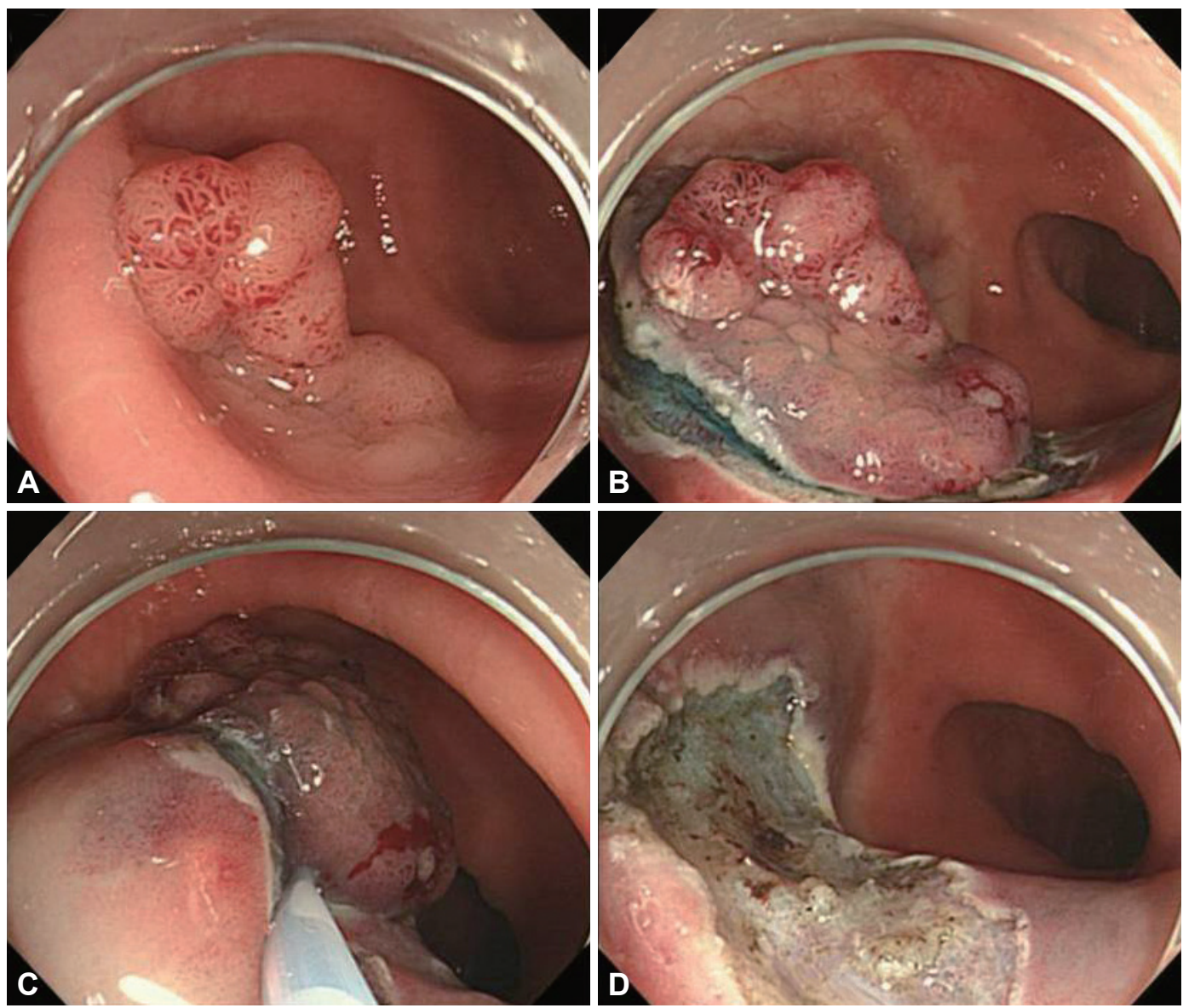

Fig. 1. Endoscopic mucosal resection with circumferential incision (EMR-CI). (A) A laterally spreading tumor, granular type was noted. (B) After submucosal injection of glycerol, a circumferential incision was performed. (C) Mucosal resection by snare was performed. (D) Successful EMR-Cl was achieved.

\section{RESULTS}

From February 2009 to March 2011, we performed EMRCI on 80 colorectal polyps. Fifty-one of 80 patients (63.8\%) were male, and the median age (range) was 60 years (range, 33 to 82). The median diameter of polyps was $25 \mathrm{~mm}$ (range, 20 to 50 ), and more than half of the polyps were located in the right colon. Morphologically, lesions were classified as Is $(n=13)$, LST-G $(n=37)$, and LST-NG $(n=30)$. Two cases involved polyps located in the cecum, and both of these were LST-Gs. According to histological findings after EMR-CI, $50 \%$ of the patients had advanced pathology because of large polyp size; high-grade dysplasia (20/80,25\%), mucosal cancer (18/80, 22.5\%), and submucosal cancer (2/80, 2.5\%).

Clinicopathologic characteristics according to polyp morphology are shown in Table 1. The sizes and histologic findings of polyps were not significantly different according to polyp morphology. However, Is polyps showed a tendency for larger size ( $\geq 30 \mathrm{~mm}$ diameter in $7 / 13,53.8 \%$ ), and the polyp location between different tumor morphologies was significantly different; Is polyps were mostly located in the rectum
(9/13, 69.2\%), and LST-Gs and LST-NGs were mostly located in the right colon (25/37, 67.6\%; and 25/30, 83.3\%; $p<0.01)$.

The clinical outcomes of endoscopic treatment are shown in Table 2. EMR-CI was successfully performed in all patients; complete endoscopic resection was performed (79/80, 98.8\%) in all patents except in one who required additional surgery due to deep submucosal invasion (depth of submucosal invasion, 2,375 $\mu \mathrm{M}$ ) identified in the post-EMR specimen. The en bloc resection rate was $66.3 \%(53 / 80)$, and the complete histologic resection rate was $45.0 \%$ (36/80). Local recurrence was not observed in any case. Although we could not identify an accurate rate of hot biopsy ablation due to the retrospective nature of the study, we assumed that was more than 33.7\% because hot biopsy ablation was performed in all cases of piecemeal resection. With regard to complications, only perforation occurred, and this was identified in five patients (6.3\%). The characteristics of polyps in patients with perforation were as follows: polyp sizes ranged from 25 to $40 \mathrm{~mm}$; polyp morphologies were Is $(n=1)$, LST-G $(n=1)$, and LSTNG ( $n=3)$; and polyps were located in the transverse colon $(n=3)$ and hepatic flexure $(n=2)$. Among patients with perfo- 

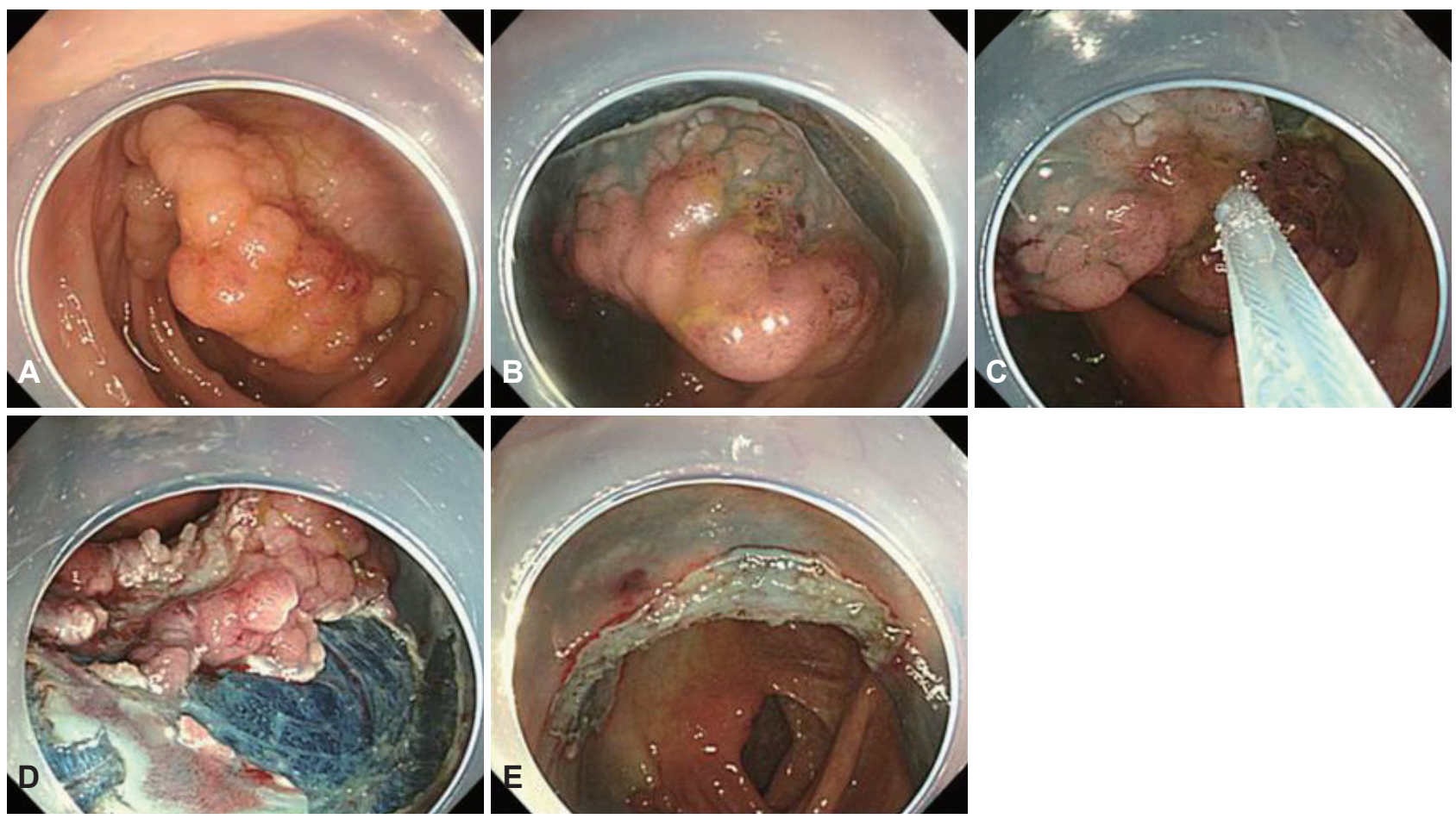

Fig. 2. Endoscopic mucosal resection with circumferential incision and piecemeal resection. (A) A laterally spreading tumor, granular type was noted. (B) After submucosal injection of glycerol, a circumferential incision was performed. (C) After circumferential incision, piecemeal resection was first performed in the large, nodular section. (D) Remnant tumor tissue was sequentially resected with piecemeal technique. (E) Successful piecemeal resection was achieved.

Table 1. Clinicopathologic Characteristics according to Polyp Morphology

\begin{tabular}{ccccc}
\hline Characteristic & Is & LST-G & LST-NG & $p$-value \\
\hline $\begin{array}{l}\text { Number } \\
\text { Size, mm }\end{array}$ & $13(16.3)$ & $37(46.3)$ & $30(37.5)$ & \\
$20-29$ & $6(46.2)$ & $22(59.5)$ & $15(83.3)$ & 0.16 \\
$30-39$ & $4(30.8)$ & $12(32.4)$ & $2(11.1)$ & \\
$40-49$ & $2(15.3)$ & $2(5.4)$ & $1(5.5)$ & \\
$\geq 50$ & $1(7.7)$ & 0 & 0 & \\
Location & & & & $<0.01$ \\
Right colon & $2(15.4)$ & $25(67.6)$ & $25(83.3)$ & \\
Left colon & $2(15.4)$ & $4(12.8)$ & $5(16.7)$ & \\
Rectum & $9(69.2)$ & $8(21.6)$ & 0 & \\
Pathology & & & & \\
Adenoma & & & & \\
LGD & $4(30.8)$ & $19(51.4)$ & $17(56.7)$ & \\
HGD & $2(15.4)$ & $11(29.7)$ & $7(23.3)$ & \\
Adenocarcinoma & & & & \\
Mucosa & $7(53.8)$ & $7(18.9)$ & $4(13.3)$ & \\
Submucosa & 0 & 0 & $2(6.7)$ & \\
\hline
\end{tabular}

Values are presented as number (\%).

Is, sessile polyp; LST-G, laterally spreading tumor-granular type; LST-NG, laterally spreading tumor-nongranular type; LGD, low grade dysplasia; HGD, high grade dysplasia. ration, the perforation occurred after snaring in four cases and during $\mathrm{CI}$ in one case, and en bloc resection was performed in three cases. All cases with perforation underwent endoscopic closure with hemoclips, and patients then fasted for 7 days and were maintained by parenteral nutrition and broad-spectrum intravenous antibiotics. A liquid diet was permitted 7 days after EMR if patients did not experience worsening of symptoms or fever, and the patients were discharged 10 days after EMR.

The clinical characteristics between en bloc and piecemeal resection are summarized in Table 3 . The majority of en blocresected tumors were $<30 \mathrm{~mm}$ in diameter $(41 / 53,77.4 \%)$, and the size of polyps between the cases undergoing en bloc and piecemeal resection was significantly different $(p<0.01)$. However, the locations and morphologies of polyps were not significantly different between the two groups.

\section{DISCUSSION}

This study aimed to evaluate the clinical outcomes of EMRCI for the treatment of large Is polyps and LSTs in the colorectum. The rate of successful endoscopic removal was 100\% despite the median lesion size of $25 \mathrm{~mm}$. In our study, the en bloc resection rate was $66.3 \%$ (53/80), which was superior to that of conventional EMR (reported as $7 \%$ to $34 \%$ for large 
Table 2. Clinical Outcomes for Endoscopic Treatment

\begin{tabular}{lc}
\multicolumn{1}{c}{ Parameter } & Value \\
\hline Complete endoscopic resection & $79(98.8)$ \\
Follow-up period, mo & $23(3-47)$ \\
En bloc or piecemeal resection & \\
En bloc & $53(66.3)$ \\
2-piece & $13(16.25)$ \\
3-piece & $6(7.5)$ \\
$\geq 4$-piece & $8(10)$ \\
Complete histologic resection & $36(45.0)$ \\
Procedure time, min & $22(7-60)$ \\
Complication & \\
Perforation & $5(6.3)$ \\
Early or delayed bleeding & 0 \\
Recurrence rate & 0 \\
\hline
\end{tabular}

Values are presented as number (\%) or median (range).

Table 3. Clinical Characteristics between En bloc Resection and Piecemeal Resection

\begin{tabular}{lccc}
\hline Characteristic & $\begin{array}{c}\text { En bloc } \\
\text { resection } \\
(n=53)\end{array}$ & $\begin{array}{c}\text { Piecemeal } \\
\text { resection } \\
(n=27)\end{array}$ & $p$-value \\
\hline Tumor size, mm & $41(77.4)$ & $12(44.4)$ & $<0.01$ \\
$20-30$ & $12(22.6)$ & $8(29.6)$ & \\
$30-40$ & 0 & $5(18.5)$ & \\
$40-49$ & 0 & $2(7.4)$ & \\
$\geq 50$ & & & 0.72 \\
Location & $35(66.0)$ & $17(63.0)$ & \\
Right colon/cecum & $8(15.1)$ & $3(11.1)$ & \\
Left colon & $10(18.9)$ & $7(25.9)$ & \\
Rectum & & & 0.57 \\
Morphology & $7(13.2)$ & $6(22.2)$ & \\
Is & $25(47.2)$ & $12(44.4)$ & \\
LST-G & $21(39.6)$ & $9(33.3)$ & \\
LST-NG & & & \\
\hline
\end{tabular}

Values are presented as number (\%).

Is, sessile polyp; LST-G, laterally spreading tumor-granular type; LST-NG, laterally spreading tumor-nongranular type.

sessile polyps), ${ }^{22,23}$ and was comparable to other studies of EMR-CI, which have reported en bloc resection rates ranging from $55.1 \%$ to $68 \%{ }^{17,19,20}$ Furthermore, when we evaluated clinical characteristics between en bloc and piecemeal resection, only polyp size was found to influence the en bloc resection rate, especially in polyps $\leq 30 \mathrm{~mm}$ in diameter. This result means that EMR-CI can be used to achieve en bloc resection regardless of tumor morphology and location if the polyp size is $<30 \mathrm{~mm}$.

Achieving clear resection margins without tumorous tissue in the specimen margins is the most desirable goal of curative procedures. In contrast with gastric tumors, peritumoral marking before endoscopic incision is not commonly required for colorectal polyps since the margin of colorectal polyps can be clearly recognized. In our study, the complete histologic resection rate was only $45 \%$, even though the en bloc resection rate was $66.3 \%$. This result was different from those of two different studies on EMR-CI, which reported complete histologic resection rates of $17 \%$ and $59.4 \% .^{19,20}$ This difference can be explained by the safety margins used in each study. We, as well as Sakamoto et al., ${ }^{19}$ performed marginal incision $2 \mathrm{~mm}$ away from the polyp during $\mathrm{CI}$, while Lee et al. ${ }^{20}$ performed marginal incision 5 to $10 \mathrm{~mm}$ away from the polyp. These different methods may influence the complete histologic resection rate of EMR-CI. Furthermore, the low complete histologic resection rate was related to thermal injury of the marginal tissue, which occurred during $\mathrm{CI}$ and trimming; moreover, marginal tissue easily chipped off during the fixation of resected lesions. Therefore, smaller safety margins may cause unintended results such as positive or indefinite resection margins in pathological reports despite complete resection. However, low complete histologic resection rates are not always related to high recurrence rates. This observation might explain the low local recurrence rate or lack of local recurrence despite the low complete histologic resection rate in our study and that of Sakamoto et al. ${ }^{19}$

Complications such as early or delayed bleeding and postpolypectomy coagulation syndrome did not occur in any of the patients. However, perforation developed in five patients $(5 / 80,6.3 \%)$. Previous studies have reported perforation rates ranging from $0 \%$ to $1.2 \%$ for EMR and $1.4 \%$ to $10.4 \%$ for ESD. ${ }^{5,9,23}$ Our perforation rate was higher than those of previous studies with EMR-CI, ranging from $0 \%$ to $3.5 \% .{ }^{17,19,20}$ This high perforation rate may be related to the location of tumors and the use of glycerol solution instead of sodium hyaluronate for submucosal lifting. Among the five cases, four perforations occurred after snaring and one perforation occurred during CI (Fig. 3). Perforation occurring after snaring could be related to inadequate lifting of the central portion of the polyp, especially if the lesion was located on a fold. Perforation in such cases might occur more frequently because the proper muscle layer may be easily grasped during snaring if the polyp is located on a fold. Furthermore, glycerol solution is less effective at submucosal lifting than sodium hyaluronate, which is widely known to provide excellent height and duration of lifting after submucosal injection. Because we did not use sodium hyaluronate solution for submucosal injection, we believe that inadequate lifting contributed to the relatively high perforation rate. Therefore, adequate lifting using sodium hyaluronate solution may be required to prevent per- 

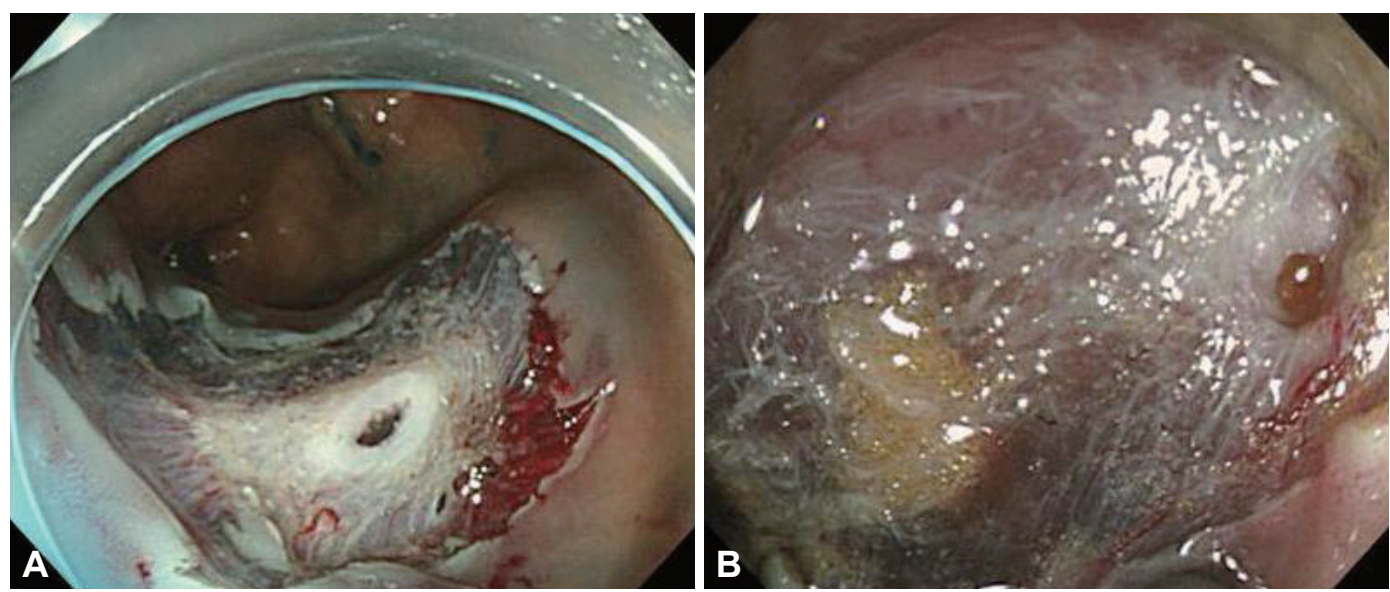

Fig. 3. Perforation caused by endoscopic mucosal resection with circumferential incision. (A) Perforation after snare resection was observed. (B) Perforation during circumferential incision was observed.

foration in EMR-CI, especially in cases of tumors located on folds.

Local recurrence did not develop in any of our cases. EMRCI can overcome the problems of positive lateral margins associated with EMR and can help clean up remnants of the lesion or normal mucosa within the incision line after CI. This result is supported by previous studies, which have reported similar local recurrence rates ranging from $0 \%$ to $17.8 \%{ }^{17,19,20}$ Because the target lesion, including an adequate safety margin, can be clearly identified by CI before snaring in EMR-CI, it is more likely that complete histologic resection will occur with this technique. Moreover, the low recurrence rate in our report is explained by the fact that we removed all grossly remnant mucosa within the incision line by hot biopsy after EMR-CI. Because other reports also had short follow-up periods ranging from 6 to 16 months, we do not believe that our follow-up period was too short in comparison. ${ }^{17,19,20}$ However, the short follow-up period in our study may have influenced the recurrence rate. Intensive and long follow-up endoscopic surveillance has been advocated after EMR, with average colonoscopy surveillance intervals of 3, 6, and 12 months. ${ }^{24}$

Recent advances in endoscopic technique have enabled the development of procedures such as endoscopic piecemeal mucosal resection (EPMR) and ESD for the removal of large polyps. The mean procedure times for $\mathrm{EPMR}^{13,25}$ and $\mathrm{ESD}^{14,25}$ range from 29 to 55 minutes, and from 70.5 to 108 minutes, respectively. With regard to the complications, the perforation rates for $\mathrm{EPMR}^{11,25,26}$ and $\mathrm{ESD}^{13,14,25}$ range from $0.8 \%$ to $1.3 \%$ and $6.2 \%$ to $10.0 \%$, respectively. However, Saito et al. ${ }^{25}$ reported that EPMR resulted in a higher recurrence rate compared with ESD ( $14 \%$ vs. $2 \%$ ). The procedure time for EMR-CI in our report (22 minutes [range, 7 to 60 ]) was shorter than that of ESD, and the perforation rate was not considerably higher than that of ESD. Although our study reported a considerably high en bloc resection rate, and low complication and recur- rence rates for ESD, we believe that if EMR-CI procedure experiences are accumulated, the clinical outcomes such as en bloc resection rate, complication rate, and recurrence rate will be better than those of ESD. ${ }^{27}$ Although we could not analyze our results statistically, we could identify increasing trends of en bloc resection rates and decreasing trends of perforation rates over time.

This study had two limitations. First, since it was a retrospective study based on historical controls treated during different periods, several biases including selection bias may be present. Second, the number of patients included in this study and the follow-up duration were limited. As the median follow-up was 23 months, tumor recurrence may have been underestimated.

In conclusion, although the perforation rate was higher than that of ESD, EMR-CI may be an effective technique for the treatment of large ( $\geq 20 \mathrm{~mm}$ diameter) Is polyps and LSTs in the colorectum, based on the finding that similar clinical outcomes are noted. In particular, EMR-CI is a more simple technique and allows shorter procedure times. Although EMR-CI for 20 to $30 \mathrm{~mm}$-sized colorectal polyps can achieve high en bloc resection rates while avoiding perforation and piecemeal resection, ESD may be the preferred method for $>30 \mathrm{~mm}$-sized colorectal polyps that can be resected piecemeally. However, EMR-CI may be considered as a second line therapeutic option if ESD is difficult.

\section{Conflicts of Interest}

The authors have no financial conflicts of interest.

\section{Acknowledgments}

This work was supported by Pusan National University Research Grant (2011).

\section{REFERENCES}

1. Van Gossum A, Cozzoli A, Adler M, Taton G, Cremer M. Colonoscop- 
ic snare polypectomy: analysis of 1485 resections comparing two types of current. Gastrointest Endosc 1992;38:472-475.

2. Kudo S. Endoscopic mucosal resection of flat and depressed types of early colorectal cancer. Endoscopy 1993;25:455-461.

3. Saito Y, Fujii T, Kondo H, et al. Endoscopic treatment for laterally spreading tumors in the colon. Endoscopy 2001;33:682-686.

4. Ahmad NA, Kochman ML, Long WB, Furth EE, Ginsberg GG. Efficacy, safety, and clinical outcomes of endoscopic mucosal resection: a study of 101 cases. Gastrointest Endosc 2002;55:390-396.

5. Hurlstone DP, Sanders DS, Cross SS, et al. Colonoscopic resection of lateral spreading tumours: a prospective analysis of endoscopic mucosal resection. Gut 2004;53:1334-1339.

6. Kiesslich R, Neurath MF. Endoscopic mucosal resection: an evolving therapeutic strategy for non-polypoid colorectal neoplasia. Gut 2004; 53:1222-1224.

7. Puli SR, Kakugawa Y, Gotoda T, Antillon D, Saito Y, Antillon MR. Meta-analysis and systematic review of colorectal endoscopic mucosal resection. World J Gastroenterol 2009;15:4273-4277.

8. Soetikno RM, Inoue H, Chang KJ. Endoscopic mucosal resection. Current concepts. Gastrointest Endosc Clin N Am 2000;10:595-617.

9. Tanaka S, Haruma K, Oka S, et al. Clinicopathologic features and endoscopic treatment of superficially spreading colorectal neoplasms larger than 20 mm. Gastrointest Endosc 2001;54:62-66.

10. Tamura S, Nakajo K, Yokoyama Y, et al. Evaluation of endoscopic mucosal resection for laterally spreading rectal tumors. Endoscopy 2004; 36:306-312.

11. Walsh RM, Ackroyd FW, Shellito PC. Endoscopic resection of large sessile colorectal polyps. Gastrointest Endosc 1992;38:303-309.

12. Conio M, Repici A, Demarquay JF, Blanchi S, Dumas R, Filiberti R. EMR of large sessile colorectal polyps. Gastrointest Endosc 2004;60: 234-241.

13. Salama M, Ormonde D, Quach T, Ee H, Yusoff I. Outcomes of endoscopic resection of large colorectal neoplasms: an Australian experience. J Gastroenterol Hepatol 2010;25:84-89.

14. Tanaka S, Oka S, Kaneko I, et al. Endoscopic submucosal dissection for colorectal neoplasia: possibility of standardization. Gastrointest Endosc 2007;66:100-107.

15. Uraoka T, Kato J, Ishikawa S, et al. Thin endoscope-assisted endoscopic submucosal dissection for large colorectal tumors (with videos). Gastrointest Endosc 2007;66:836-839.
16. Sakamoto N, Osada T, Shibuya T, et al. Endoscopic submucosal dissection of large colorectal tumors by using a novel spring-action S-O clip for traction (with video). Gastrointest Endosc 2009;69:1370-1374.

17. Repici A, Conio M, De Angelis C, et al. Insulated-tip knife endoscopic mucosal resection of large colorectal polyps unsuitable for standard polypectomy. Am J Gastroenterol 2007;102:1617-1623.

18. Hirao M, Masuda K, Nakamura M. Endoscopic resection with local injection of HSE (ERHSE) in early gastric carcinomas. Gan No Rinsho 1986;32:1180-1184.

19. Sakamoto T, Matsuda T, Nakajima T, Saito Y. Efficacy of endoscopic mucosal resection with circumferential incision for patients with large colorectal tumors. Clin Gastroenterol Hepatol 2012;10:22-26.

20. Lee EJ, Lee JB, Lee SH, Youk EG. Endoscopic treatment of large colorectal tumors: comparison of endoscopic mucosal resection, endoscopic mucosal resection-precutting, and endoscopic submucosal dissection. Surg Endosc 2012;26:2220-2230.

21. Participants in the Paris Workshop. The Paris endoscopic classification of superficial neoplastic lesions: esophagus, stomach, and colon: November 30 to December 1, 2002. Gastrointest Endosc 2003;58(6 Suppl):S3-S43.

22. Ah Soune P, Menard C, Salah E, Desjeux A, Grimaud JC, Barthet M. Large endoscopic mucosal resection for colorectal tumors exceeding 4 $\mathrm{cm}$. World J Gastroenterol 2010;16:588-595.

23. Brooker JC, Saunders BP, Shah SG, Williams CB. Endoscopic resection of large sessile colonic polyps by specialist and non-specialist endoscopists. Br J Surg 2002;89:1020-1024.

24. Iishi $\mathrm{H}$, Tatsuta M, Iseki K, et al. Endoscopic piecemeal resection with submucosal saline injection of large sessile colorectal polyps. Gastrointest Endosc 2000;51:697-700.

25. Saito Y, Fukuzawa M, Matsuda T, et al. Clinical outcome of endoscopic submucosal dissection versus endoscopic mucosal resection of large colorectal tumors as determined by curative resection. Surg Endosc 2010;24:343-352.

26. Zlatanic J, Waye JD, Kim PS, Baiocco PJ, Gleim GW. Large sessile colonic adenomas: use of argon plasma coagulator to supplement piecemeal snare polypectomy. Gastrointest Endosc 1999;49:731-735.

27. Tanaka S, Terasaki M, Kanao H, Oka S, Chayama K. Current status and future perspectives of endoscopic submucosal dissection for colorectal tumors. Dig Endosc 2012;24(Suppl 1):73-79. 